\title{
PARALLEL GROWTHS
}

\author{
Joel David \\ College of Social Sciences \\ Inha University
}

Kritika Kultura and my current academic career (my third, after teaching in Pinas and completing graduate school in the US) intersected when I was scouting around for receptive journals in order to fulfill my tenure requirements. Lulu Torres Reyes, whom I had known from an informal film-appreciation group before either of us started teaching, told me about a journal she was editing and invited me to contribute an article on film. $K K$ turned out to be a cultural studies publication, entirely in sync with my specialization. After my first article, I proposed a forum topic, then an omnibus monograph, then a second and third forum, all on cinema; along the way I also delivered the first of $K K$ 's Global Classroom Series and lectured in the same Ateneo English Department that housed the journal. I also earned my tenure, but that marker barely registered with me. All I kept wanting to do was watch $K K$ grow and enjoin the other journals I was involved in to mimic $K K$ 's open-access strategy. I even set up my personal blog, Ámauteurish! (at https:// amauteurish.com), in a similar manner, and got cited for it in recognitions given by various bodies including the San Francisco-based Filipino Arts \& Cinema International. The first $K K$ forum I handled, on Ishmael Bernal's 1980 film Manila by Night, earned me an invitation to contribute to Arsenal Pulp Press's acclaimed Queer Film Classics series (the book, Manila by Night: A Queer Film Classic, came out recently). Until this invitation to provide a testimonial for $K K$ 's 30 th issue, I never realized how closely intertwined my professional trajectory has been with the journal. Each of the areas I ventured to explore as a film scholar-film form, narratology, gender issues, genre, star texts-made their mark via articles that came out in $K K$.

The question that I'm trying to think through is: what about the next 30 issues (which would also be the journal's 3oth year)? Any media scholar will have to 
admit to the crucial element of unpredictability, since the technology, politics, and economy of popular culture are still in the process of shifting. "Evolving" would be the ideal term, but seems too presumptuous given the recent dystopic "developments" in social-media networks.) Moreover, to my relief, I would be conveniently retired long before then. But I can safely attest to certain factors that would be resilient to these upheavals that we're witnessing: the need for academics to continue critiquing present and future knowledge, and the need for people to uncover new sources of mediated pleasures. Scholarship on entertainment: not as easy as it sounds, and rarely as entertaining either, but essential to our continuing understanding of our world. 